\title{
Groundwater Quality in the Southern Sacramento Valley, California
}

Groundwater provides more than $\mathbf{4 0}$ percent of California's drinking water. To protect this vital resource, the State of California created the Groundwater Ambient Monitoring and Assessment (GAMA) Program. The Priority Basin Project of the GAMA Program provides a comprehensive assessment of the State's groundwater quality and increases public access to groundwater-quality information. The Southern Sacramento Valley is one of the study units being evaluated.

\section{The Southern Sacramento Valley Study Unit}

The Southern Sacramento Valley (SSA CV ) study unit is located in California's Sacramento Valley. The 2,100-square-mile study unit includes five groundwater subbasins: N orth A merican, Solano, South A merican, Suisun-Fairfield, and Yolo (California Department of Water Resources, 2003). A n additional study area, South Sacramento U plands, was created within portions of the N orth and South A merican groundwater subbasins. In the SSA CV study unit, summers are hot and dry and winters are cool and moist. Average annual rainfall ranges from 17 to 23 inches. M ost rivers and streams flowing across the study unit drain into the Sacramento River, which then flows into the Sacramento-San J oaquin D elta and the San

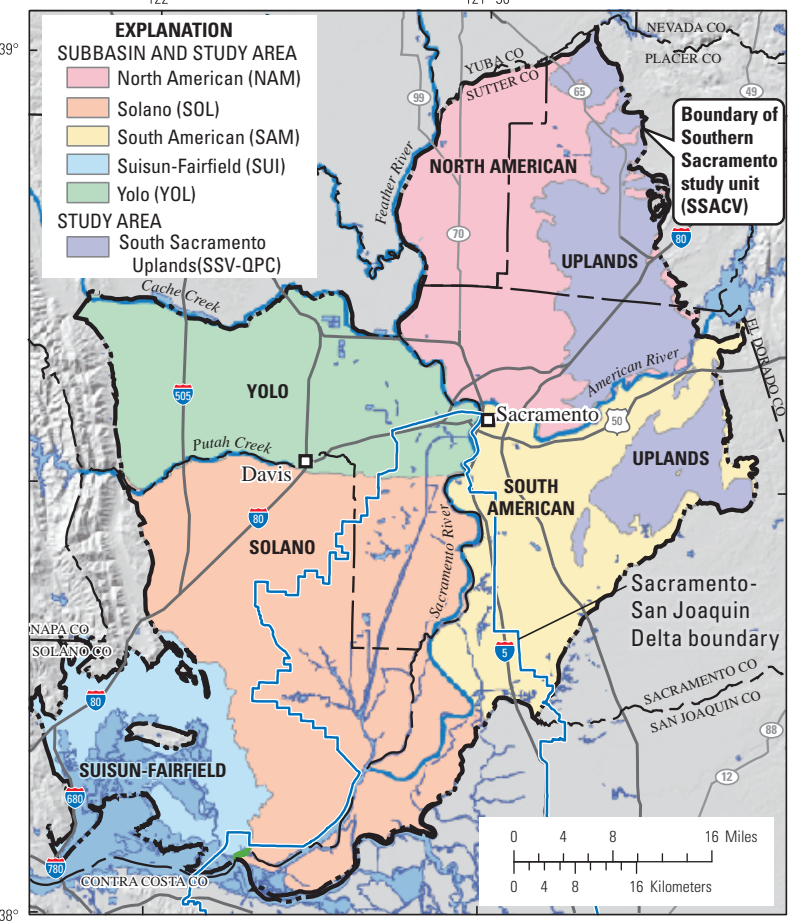

Francisco B ay estuary.

A quifers in the SSA CV study unit consist of discontinuous lenses of gravel, sand, silt, and clay, which primarily are derived from the Sierra $\mathrm{N}$ evada mountains ranges to the east and the Coast $R$ anges to the west. The primary aquifers in the SSACV study unit are defined as those parts of the aquifers corresponding to the perforated intervals of wells listed in the California Department of Public Health (CDPH) database. The publicsupply wells monitored by the CDPH typically are completed within the primary aquifers to depths of 250-500 feet below land surface (bls). The wells are constructed with solid casing from the land surface to a depth of about 150-250 feet bls, and are perforated below

the solid casing to allow water into the well. Water quality in the primary aquifers may differ from water quality in shallow or deep parts of the aquifer system.

Land use in the study unit is about 53 percent (\%) agricultural, 33\% natural (primarily grassland), and 14\% urban. The City of Sacramento is the largest urban area in the study unit.

Recharge to the groundwater flow system primarily is from rivers and streams draining the Sierra N evada and the Coast Ranges, and from infiltration of precipitation and of surface water applied for irrigation (California D epartment of Water R esources, 2003). The primary sources of groundwater discharge (water leaving the flow system) are pumping for irrigation and municipal water supply, evaporation from areas with a shallow depth to water, and discharge to streams.

\section{Overview of Water Quality}
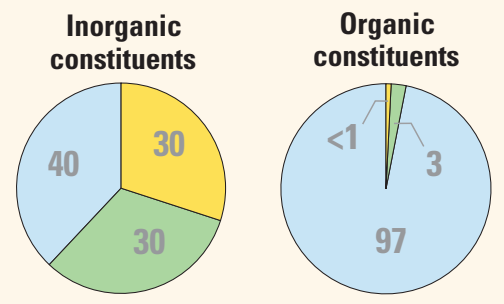

CONSTITUENT CONCENTRATIONS

High $\bigcirc$ Moderate $\bigcirc$ Low or not detected

Values are a percentage of the area of the primary aquifers with concentrations in the three specified categories.

GA M A's Priority B asin Project evaluates the quality of untreated groundwater; however, for context, benchmarks established for drinking-water quality are used for comparison. B enchmarks, and definitions of high, moderate, and low concentrations, are discussed in the inset box," Benchmarks for Eval uating Groundwater Quality" on page 3.

$M$ any inorganic constituents occur naturally in groundwater. The concentrations of the inorganic constituents can be affected by natural processes, as well as by human activity. In the SSA CV study unit, one or more inorganic constituents were detected at high concentrations in about $30 \%$ of the primary aquifers and at moderate concentrations in about $30 \%$.

Organic constituents are present in products used in the home, business, industry, and agriculture. Organic constituents can enter the environment through normal usage, spills, or improper disposal. In the SSA CV study unit, one or more organic constituents were detected at high concentrations in less than $(<) 1 \%$ of the primary aquifers, and at moderate concentrations in $3 \%$. 


\section{RESULTS: Groundwater Quality in the Southern Sacramento Valley Study Unit}

\section{INORGANIC CONSTITUENTS}
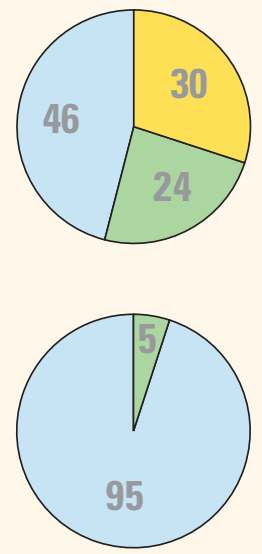

\section{Radioactive} constituents
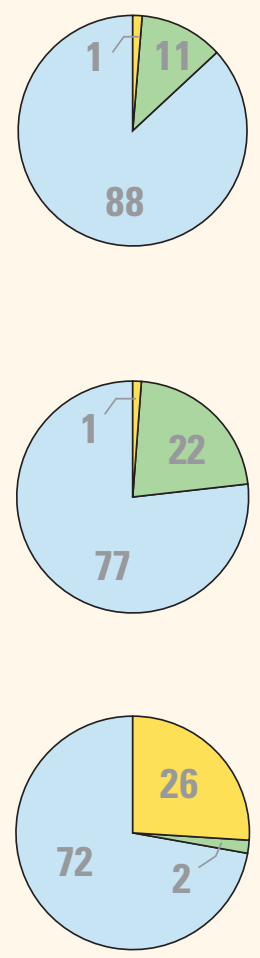

Iron or manganese
SPECIAL-INTEREST CONSTITUENTS

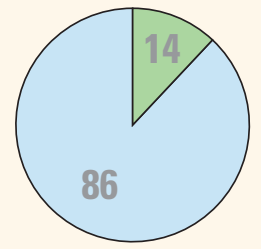

\section{Perchlorate}

\section{Inorganic Constituents with Human-Health Benchmarks}

Trace and minor elements are naturally present in the minerals in rocks and soils, and in the water that comes into contact with those materials. In the SSA CV study unit, one or more trace elements were detected at high concentrations in about $30 \%$ of the primary aquifers. A rsenic and boron were the two trace el ements that were most frequently detected at concentrations greater than benchmarks. A luminum, chromium, and lead also were detected at high concentrations, but only in $<1 \%$ of the primary aquifers.

Radioactivity is the release of energy or energetic particles during structural changes in the nucleus of an atom. M ost of the radioactivity in groundwater comes from decay of naturally occurring isotopes of uranium and thorium in minerals in the sediments of the aquifers. In the SSA CV study unit, radioactive constituents were not detected at high concentrations, but were detected at moderate concentrations in about $5 \%$ of the primary aquifers.

N utrients, such as nitrate and nitrite, are naturally present at low concentrations in groundwater. High and moderate concentrations generally occur as a result of human activities, and can come from fertilizer applied to crops and landscaping, seepage from septic systems, and human and animal waste. In the SSA CV study unit, nutrients were detected at high concentrations in about $1 \%$ of the primary aquifers and at moderate concentrations in about $11 \%$.

\section{Inorganic Constituents with Non-Health Benchmarks}

(Not included in water-quality overview charts shown on the front page)

Some constituents affect the aesthetic properties of water, such as taste, color, or odor, or may create nuisance problems, such as staining and scaling. The State of California has a recommended and an upper limit for total dissolved solids (TDS) in drinking water. In the SSA CV study unit, TDS concentrations were high (greater than the upper limit) in about 1\% of the primary aquifers and were moderate in about $22 \%$.

Iron and manganese are naturally occurring el ements that of ten co-occur. Iron or manganese concentrations (or both) were present at high concentrations in about $26 \%$ of the primary aquifers and at moderate concentrations in about $2 \%$.

\section{Perchlorate}

(Not included in water-quality overview charts shown on the front page)

Perchlorate is an inorganic constituent that has been regulated in California drinking water since 2007. It is an ingredient in rocket fuel, fireworks, safety flares, and other products, may be present in some fertilizers, and al so occurs naturally at low concentrations in groundwater.

In the SSA CV study unit, perchlorate was not detected at high concentrations in the primary aquifers but was detected at moderate concentrations in about $14 \%$ of the primary aquifers. 


\section{RESULTS: Groundwater Quality in the Southern Sacramento Valley Study Unit}

\section{ORGANIC CONSTITUENTS}
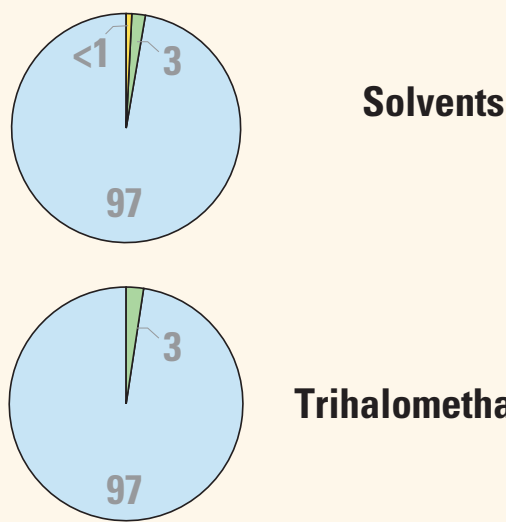

Trihalomethanes

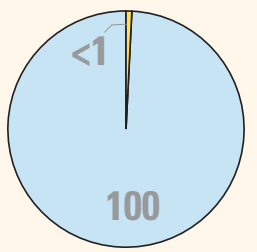

\section{Gasoline} additives

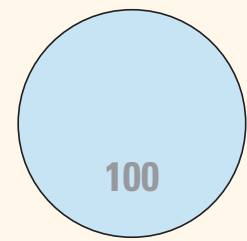

\section{Herbicides and fumigants}

Insecticides

\section{Organic Constituents}

The Priority Basin Project uses laboratory methods that can detect the presence of volatile organic compounds ( $\mathrm{VOC}$ ) and pesticides at low concentrations, far below human-health benchmarks. VOCs and pesticides detected at these low concentrations can be used to trace the pathways of water from the landscape into the aquifer system.

\section{Volatile Organic Compounds with Human-Health Benchmarks}

VOCs are present in many household, commercial, industrial, and agricultural products, and are characterized by their tendency to volatilize into the air.

Solvents are used for a number of purposes, including manufacturing and cleaning. In the SSA CV study unit, solvents were detected at high concentrations in $<1 \%$ of the primary aquifers, at moderate concentrations in about $3 \%$, and at low concentrations (or not detected) in about $97 \%$. The solvent present at high concentrations was perchloroethene (PCE).

Trihalomethanes form during disinfection of water supplies and may enter groundwater by the infiltration of landscape irrigation or leaking water-distribution lines. Trihal omethanes were not detected at high concentrations in the primary aquifers, and were detected in moderate concentrations in about 3\% of the primary aquifers.

Gasoline additives are added to gasoline to make it burn more efficiently. Gasoline additives were detected at high concentrations in $<1 \%$ of the primary aquifers. The gasoline additive present at high concentrations was tert-butyl alcohol.

\section{Pesticides with Human-Health Benchmarks}

Pesticides (herbicides, insecticides, and fumigants) are applied to crops, lawns, gardens, around buildings, and along roads, to help control weeds, insects, fungi, and other pests. In the SSA CV study unit, pesticides were not detected at high concentrations in the primary aquifers. Insecticides were detected at moderate concentrations in about $1 \%$ of the primary aquifers. Herbicides and fumigants were detected at low concentrations.

\section{BENCHMARKS FOR EVALUATING GROUNDWATER QUALITY}

GA M A's Priority B asin Project uses benchmarks established for drinking water to provide context for evaluating the quality of untreated groundwater. A fter withdrawal, groundwater may be disinfected, filtered, mixed, and exposed to the atmosphere before being delivered to consumers. Federal and $\mathrm{C}$ alifornia regulatory benchmarks for protecting human health ( $M$ aximum Contaminant L evel, M CL) are used for the evaluation when available. Otherwise, non-regulatory benchmarks for protecting aesthetic properties (Secondary M aximum Contaminant L evel, SM CL) such as taste and odor, and non-regulatory benchmarks for protecting human health (Notification L evel, NL, and L ifetime Health A dvisory, HAL), are used.

\section{High, moderate, and low concentrations are defined relative to benchmarks}

Concentrations are considered high if they are greater than a benchmark. For inorganic constituents, concentrations are moderate if they are greater than one-half of a benchmark. For organic and special-interest constituents, concentrations are moderate if they are greater than one-tenth of a benchmark; this lower threshold was used because organic constituents generally are less preval ent and have smaller concentrations relative to benchmarks than inorganic constituents. Low includes nondetections and values less than moderate concentrations. M ethods for evaluating water quality are discussed in B ennett and others (2010).

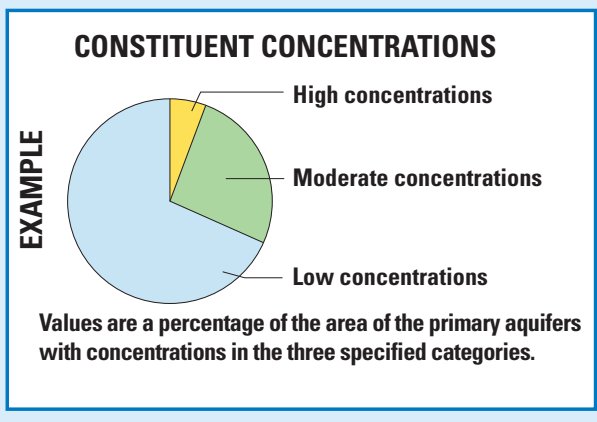




\section{Arsenic and Boron in the Southern Sacramento Valley Study Unit}

A rsenic and boron were the trace elements that most frequently occurred at high concentrations in the SSA CV study unit. A rsenic was detected at concentrations greater

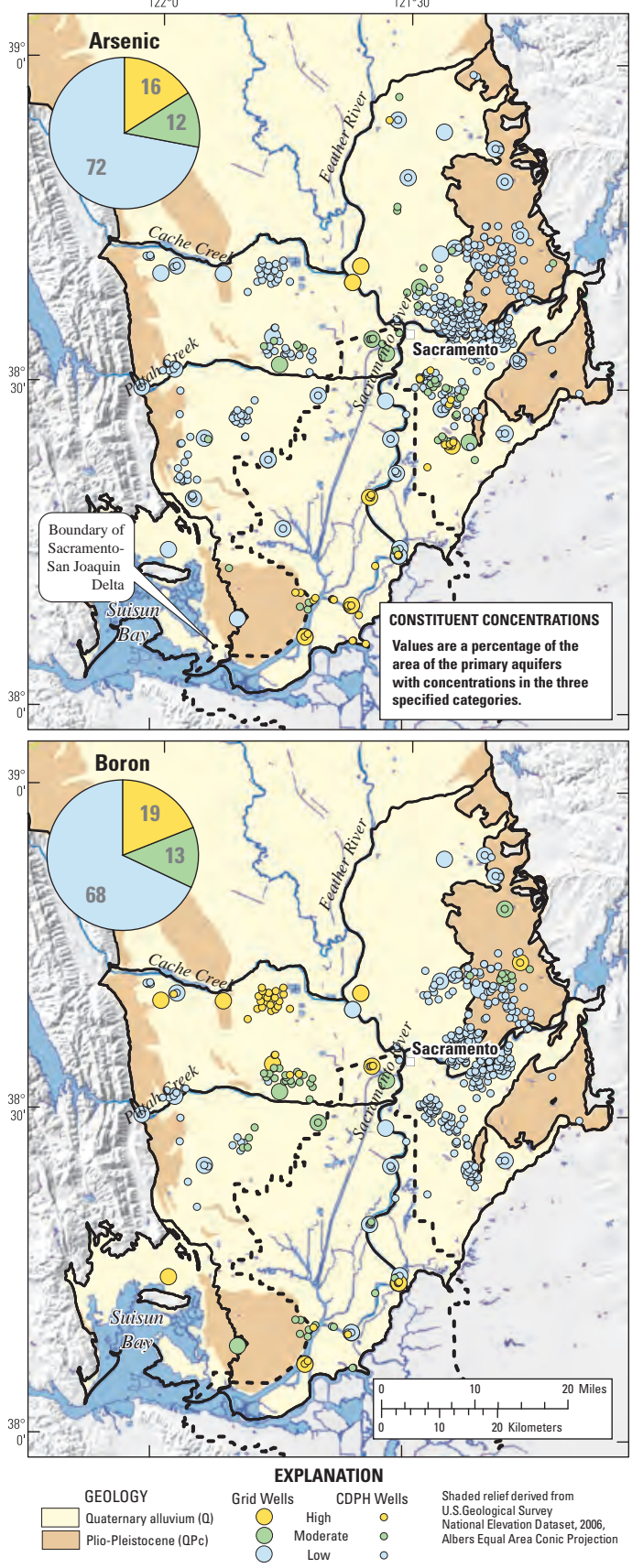

than the regulatory $M C L$ benchmark of 10 micrograms per liter $(\mu \mathrm{g} / \mathrm{L})$ in $16 \%$ of the primary aquifers. High concentrations of arsenic were found in wells located in the center of the Sacramento Valley al ong the Sacramento River and in wells located in the Sacramento-San J oaquin Delta. Groundwater in the Quaternary alluvial deposits al ong the River and in the Delta commonly has low dissolved oxygen content (reducing conditions), and reducing conditions are correlated with el evated arsenic concentrations in Sacramento Valley groundwater (Dawson, 2001). Boron was detected at concentrations greater than the non-regulatory human-heal th $\mathrm{NL}$ benchmark of $1,000 \mu \mathrm{g} / \mathrm{L}$ in $19 \%$ of the primary aquifers. High concentrations of boron found in wells located along Cache and Putah Creeks are likely associated with old marine sediments from the Coast R anges (B ennett and others, 2011). High concentrations of boron found in wells located near the outlet of the Delta to Suisun B ay are likely associated with estuarine sediments of the San Francisco B ay and Sacramento-San J oaquin Delta system.

\section{By G eorge L. B ennett, V,} M iranda S. Fram, and Kenneth B elitz
Priority Basin Assessments

GAM A's Priority B asin Project $(P B P)$ assesses water quality in that part of the aquifer system used for drinking water, primarily public supply. Water quality in the primary aquifers may differ from water quality in shallower and deeper parts of the aquifers. GA M A's Domestic Well Project assesses water quality in the shallower parts of the aquifer system. Ongoing assessments are being conducted in more than 120 basins throughout California.

The PBP assessments are based on a comparison between constituent concentrations in untreated groundwater and drinking-water benchmarks established for protection of human health and for aesthetic concerns. The PBP does not evaluate the quality of drinking water delivered to consumers.

The PBP uses two scientific approaches for assessing groundwater quality. The first approach uses a network of wells to statistically assess the status of groundwater quality. The second approach combines water-quality, hydrologic, geographic, and other data to hel $p$ assess the factors that affect water quality. In the SSA CV study unit, data were collected by the PBP in 2005 and from the CDPH database for 2002-05. The PBP includes chemical analyses generally not available as part of regulatory compliance monitoring, including measurements at concentrations much lower than human-health benchmarks, and measurement of constituents that can be used to trace the sources and movement of groundwater.

\section{For more information}

Technical reports and hydrologic data collected for the GA M A Program may be obtained from:

\section{GAMA Project Chief}

U.S. Geological Survey California Water Science Center 4165 Spruance R oad, Suite 200

San Diego, CA 92101

Telephone number: (619) 225-6100

WEB: http://ca.water.usgs.gov/gama

GAMA Program Unit

State Water Resources Control Board Division of Water Quality

PO B ox 2231, Sacramento, CA 95812

Telephone number: (916) 341-5779

WEB: http://www.waterboards.ca.gov/ water_issues/programs/gama Survey Data Series 285, 93 p. (Also available at $h$ ttp://pubs.usgs.gov/ds/285.) 